\title{
EDITORIAL \\ International women leaders in neurosurgery: past, present, and what the future must look like
}

\author{
Sarah Olson, MBChB, FRACS, MPhil, ${ }^{1}$ Heidi McAlpine, MBBS, BSc(Hons), ${ }^{2}$ \\ Sarah A. Cain, MBBS, BSc(Hons), ${ }^{2}$ Ruth Mitchell, MBBS, FRACS, ${ }^{3,4}$ \\ Gemma Olsson, MBBS, FRACS, ${ }^{5}$ and Katharine J. Drummond, MD, FRACS 2,3
}

\begin{abstract}
${ }^{1}$ Department of Neurosurgery, Princess Alexandra Hospital, Brisbane, Queensland; ' 2 Department of Neurosurgery, The Royal Melbourne Hospital, Parkville, Victoria; ${ }^{3}$ Department of Surgery, Faculty of Medicine, Dentistry and Health Sciences, University of Melbourne, Parkville, Victoria; ${ }^{4}$ Walter and Eliza Hall Institute for Medical Research, Parkville, Victoria; and ${ }^{5}$ Department of Neurosurgery, Westmead Hospital, Westmead, New South Wales, Australia
\end{abstract}

$\mathrm{W}$ E congratulate the Neurosurgical Focus Editorial Board for this landmark issue. However, it is timely to examine why it is extraordinary and describe the gender landscape for women neurosurgery leaders. A volume on male leaders in neurosurgery would be simply "International leaders in neurosurgery, past and present," and many of the statements below would be absurd if gender were reversed. Compare "...the greatest perceived barrier to women wanting to pursue... a career in surgery was in the incongruity with motherhood..." with "...the greatest perceived barrier to men wanting to pursue...a career in surgery was in the incongruity with fatherhood...."

\section{The Gender Landscape of Leadership in Neurosurgery}

Recognizing the lack of diversity in surgery, the Royal Australasian College of Surgeons (RACS) launched a 2016 "Diversity and Inclusion Plan," with a raft of initiatives. Target-setting was prominent, aiming for "....aspirational and achievable targets for increased representation of women in surgical education and training (SET)...by 2021." The target was $40 \%$. Despite this admirable goal, with little concrete action, the target will not be achieved. Gender disparity in Australasia continues in surgery, despite gender equity in medical school graduates since the late 20th century. Women represent only $21 \%$ of those entering neurosurgery training in 2021, and are twice as likely to discontinue training compared with their male counterparts. ${ }^{1}$

Currently, $14 \%$ of Australasian neurosurgeons are women. There is a small increment in leadership with $31 \%$ of the SET Board and 24\% of the Neurosurgical Society of Australasia (NSA) Executive Board members being women. These statistics are repeated worldwide. ${ }^{2}$ To un- derstand the causes of gender inequity in neurosurgery leadership would be a lengthy nuanced discussion, but here we outline major themes.

\section{Setting the Scene for Failure: Unconscious Bias and Microaggression}

Unconscious bias and microaggression are strongly associated with the choice to enter neurosurgical training and pursue career progression. ${ }^{3}$ Unconscious or implicit bias are attitudes or stereotypes that affect our understanding in an unconscious manner; microaggression follows, as actions subtly and often unintentionally hostile to a minority group. Both are pervasive and present throughout life and influence perception of the likelihood of a leadership career in neurosurgery. In one study, investigators sent identical resumes, but with male or female names, for application to a managerial science position. There was a significantly more favorable perception of "male" applicants' competence. Faculty were more interested in mentoring men, and a $\$ 4000$ higher salary was offered. ${ }^{4}$

Attitudes conveyed in a multitude of small ways regarding the difficulty of neurosurgery for women, particularly in relation to caregiving responsibilities, send constant subtle messages. In a study of US orthopedic surgeons, $87 \%$ of women experienced negative treatment compared to male colleagues, with up to $90 \%$ of this negative treatment directed at junior doctors. ${ }^{5}$ Behaviors included supplying women with substandard equipment, no assistant, and/or a longer wait for radiology. The message of this behavior is that women's surgical work is less important and is internalized by students, junior doctors, and surgeons, as "you can't or shouldn't be here (or lead)."

While a man's success is generally attributed to ability, a woman's success is often attributed to luck or personal 
relationships. This attitude undermines women's leadership, implying women are less capable. Additionally, the stakes are higher for poor performance: women experience higher penalties for medical mistakes. When the patient of a woman surgeon dies, referrals drop 54\%, while there is only a small reduction for men. This translates as distrust of women surgeons' skills and, by extension, their ability to lead.

\section{Disempowerment: Stereotyping and Gender Schemas}

Gender schemas are our intuitive hypotheses about behaviors and traits expected based on sex, i.e., how men and women are "supposed to behave." These strongly held stereotypes negatively influence women's career advancement. Women who behave in a confident, aggressive, and independent manner may be seen incongruous to gender schemas. They are more likely to take informal, rather than official, leadership roles. ${ }^{6}$ Women leaders must behave with exemplary competence, but also conform to appropriate female behaviors. This is an impossible juggle and in excess of that required from men, who are expected to be agentic. Conversely, women are expected to be nurturing, sensitive, warm, and communal, or incur negative characterization for violating gender schemas, regardless of what is necessary for leadership.

\section{It Is Lonely at the Top}

What is the role of women neurosurgeons in attracting women leaders? Unfortunately, they may protect themselves from gender stereotypes by distancing from or discouraging other women. Such behaviors may be triggered in male-dominated environments where women feel devalued, or where positions for women are scarce. ${ }^{6}$ Role models and mentors are often seen as the panacea for gender inequity, but when women see leaders treated poorly or behaving badly, the effect may be negative rather than positive. ${ }^{6}$

\section{The Pay Disparity}

In Australasia, the average gender pay gap in medicine is $33.6 \%$, and in some surgical specialties $60 \%, 7$ similar to those in other countries. The causes of this gap are complex. Women surgeons may be driven toward less remunerative specialties (occupational segregation). This is seen in Australasian pediatric surgery, the only surgical discipline with gender equity in trainees. ${ }^{1}$ Women perform more underpaid and unpaid "nurturing" and "collaborative" work, such as education and committees, fitting existing gender schema. The overarching message is that work done by women is less valuable.

\section{Loss of Future Women Leaders}

There are barriers to women entering and completing neurosurgery training. In Ireland, women medical students' career choices were significantly influenced by the availability of part-time work, parental leave, and working hours; surgery was not seen as conducive. The most common perceived barrier to surgery is its incongruity with motherhood and childcare (50\%). ${ }^{8}$

Women are 1.6 times more likely to be burned out than their male counterparts, particularly if they have children. ${ }^{9}$ A higher proportion of women leave specialty training. ${ }^{10}$
Lack of adequate role models, inflexibility in training, and perceptions of an "old boys club" are cited as the main reasons women exit training in the United Kingdom. ${ }^{8}$ The pressures that lead women to leave surgical training in Australia have been studied. The path to exit is characterized as an imbalanced tower of "blocks," each representing a factor contributing to dissatisfaction. One final "block," such as an episode of discrimination, stereotyping, unconscious bias, microaggression, lack of support, or burnout, may seem minor in isolation, but will topple the tower, cementing the choice to leave. ${ }^{11}$

\section{Why Do We Need Women Neurosurgical Leaders?}

This discussion usually starts with an exposition of reasons women are as good as, or better than, men in leadership arenas and thus "deserve" equity of representation in leadership. There is ample evidence that women have equivalent leadership skills to men and genuine commitment to leadership gender equity has been proven to improve performance in banking, company boards, and retail and hospitality companies. A 2015 McKinsey report concluded that narrowing the labor market gender gap would achieve an $11 \%$ boost to Australian gross domestic product by $2025 .{ }^{12}$ However, while $75 \%$ of men agree diverse leadership teams generate better performance, only $19 \%$ agree that reaching top management is more difficult for women, highlighting the challenges of achieving equity.

Similarly, in medicine, the discussion continues that women neurosurgeons (surgeons/doctors) are at least as good as, or even better than, men. Women surgeons have lower elective surgery mortality rates, readmission rates, 7,13 and incidences of medicolegal action. ${ }^{14}$ They equal or exceed male counterparts in communication, collaboration, patient centeredness, professionalism, technical skills, and clinical judgment. ${ }^{15}$ But this discussion is both irrelevant and belittling. Women should not need to show they are as capable as, equal to, or better than men. The fundamental question is not about skill, and efforts to prove worth are futile and offensive. The answer to the question, "why do we need women neurosurgical leaders" comes with aligning our aims with those of the Ottawa Consensus and similar statements, that diversity in neurosurgery and healthcare in general ${ }^{16}$ is to the benefit to the profession, and to see a moral imperative that those who provide care should be representative in the fullest sense of those for whom they care. ${ }^{17}$ This is agreed in other areas of life, most strongly in government, as discussed by Julia Gillard, Australia's only woman prime minister: " "...ultimately the case for women's leadership is a moral one. In a democracy, a population should be able to look at its leaders and see a reflection of the full diversity of society. What kind of democracy is it that bestows a vote but not a real prospect to be voted for?"

Thus, the development of women leaders in neurosurgery is imperative for the future of our profession. Without gender equity, neurosurgery becomes a progressively more obvious anachronism, not fit for purpose in the world as we now understand it or for the care of our patients. The solution will take a genuine commitment from all in power. To not understand, or even shun, rapid advancement for $50 \%$ of the population into all spheres of leadership is extraordinary. 


\section{How Do We Promote Women Neurosurgical Leaders?}

A discussion of the solutions to gender inequity in neurosurgery leadership is well beyond the scope of this paper, but major themes can be outlined. The Women in Neurosurgery (WINS) white paper ${ }^{10}$ recommended the following three strategies: eliminating discrimination, promoting women, and fostering female role models. These strategies are excellent but not enough. Structural change will be necessary. As discussed, not all role models are helpful, and powerful sponsorship of women in neurosurgery, by both men and women in leadership positions, will be most important. This cannot be seen as a "women's issue"; unless leading men actively support a gender diverse agenda, nothing will change.

Importantly, discrimination and unconscious bias in workplace policies should be acknowledged and addressed, particularly related to caregiving. Flexible working hours will be necessary, as will equity in career advancement and remuneration. These are not simple to enact and will require disruptive workplace change. ${ }^{7}$ Flexible working conditions must be carefully crafted, as less than full-time work may reduce the likelihood of reaching leadership positions. There is asymmetry in the increase in women's paid hours compared to the increase in men's family work, to the detriment of women's availability for their career. ${ }^{18}$ Progress will require increased men's participation in care work and workplace policies that encourage both men and women to combine jobs with care responsibilities.

In Australasia and elsewhere, neurosurgery has been forced to recognize sexual harassment, bullying, and discrimination as a serious problem, experienced by almost half of all surgeons, disproportionately women. ${ }^{19}$ Resources must be invested in prevention and prosecution. This is as much the role of the policy maker, and leaders in neurosurgery, as it is for peers to enforce.

Unconscious bias is more pervasive. Change will be glacial unless culture is engineered to provide a different narrative. This will only come with a commitment to diversity reflected in numbers, such as requiring appointment of equal numbers of women and men who achieve a minimum standard to neurosurgery training. This will be unpopular and disruptive and requires engagement from all levels of the neurosurgery community. In addition, women need to be appointed to leadership positions, and these women then need to support other women leaders.

The lack of female mentors and trained, willing male mentors and ineffective mentorship/sponsorship have been identified as key challenges for women in neurosurgery. ${ }^{20}$ Role modeling and mentorship are not universally positive experiences, and we, as women at varying levels of neurosurgery leadership, advocate for a model of strong supportive sponsorship for women to take and succeed in leadership opportunities; this requires recognition, compensation, mandating, and training.

\section{Conclusions}

The Australasian experience shows that simply setting targets for gender equity falls short of delivering, without disruptive proposals to achieve them. Change requires acknowledgment and understanding of a problem, a desire for change, and the means to enact change. For gender equity, individual and institutional members of the neurosurgical community must commit to change, allocate resources, and accept accountability. While we celebrate in this issue the incredible achievements of women neurosurgical leaders, we also reflect on their journey and its barriers, and consider the many outstanding women lost to our profession as casualties of gender disparity.

https://thejns.org/doi/abs/10.3171/2020.12.FOCUS20949

\section{References}

1. Royal Australasian College of Surgeons. Workforce \& activities reports. RACS Activities Report 2019. Accessed January 13, 2021. https://www.surgeons.org/en/Resources/reportsguidelines-publications/workforce-activities-reports

2. Corley J, Kim E, Philips CA, et al. One hundred years of neurosurgery: contributions of American women. J Neurosurg. 2021;134(2):337-342.

3. Marks IH, Diaz A, Keem M, et al. Barriers to women entering surgical careers: a global study into medical student perceptions. World J Surg. 2020;44(1):37-44.

4. Moss-Racusin CA, Dovidio JF, Brescoll VL, et al. Science faculty's subtle gender biases favor male students. Proc Natl Acad Sci U S A. 2012;109(41):16474-16479.

5. Cook DJ, Griffith LE, Cohen M, et al. Discrimination and abuse experienced by general internists in Canada. J Gen Intern Med. 1995;10(10):565-572.

6. Gillard J, Okonjo-Iweala N. Women and Leadership: Real Lives, Real Lessons. Penguin Random House Australia; 2020:254-273.

7. Tsugawa Y, Jena AB, Figueroa JF, et al. Comparison of hospital mortality and readmission rates for Medicare patients treated by male vs female physicians. JAMA Intern Med. 2017;177(2):206-213.

8. Bellini MI, Graham Y, Hayes C, et al. A woman's place is in theatre: women's perceptions and experiences of working in surgery from the Association of Surgeons of Great Britain and Ireland women in surgery working group. BMJ Open. 2019;9(1):e024349.

9. Elmore LC, Jeffe DB, Jin L, et al. National survey of burnout among US general surgery residents. J Am Coll Surg. 2016; 223(3):440-451.

10. Benzil DL, Abosch A, Germano I, et al. The future of neurosurgery: a white paper on the recruitment and retention of women in neurosurgery. J Neurosurg. 2008;109(3):378386.

11. Liang R, Dornan T, Nestel D. Why do women leave surgical training? A qualitative and feminist study. Lancet. 2019; 393(10171):541-549.

12. McKinsey \& Company. The Power of Parity: How Advancing Women's Equality Can Add \$12 Trillion to Global Growth. September 2015. Accessed January 13, 2021. https: //www.mckinsey.com/ /media/McKinsey/Industries/Public and Social Sector/Our Insights/How advancing womens equality can add 12 trillion to global growth/MGI Power of parity_Full report_September 2015.pdf

13. Wallis CJ, Ravi B, Coburn N, et al. Comparison of postoperative outcomes among patients treated by male and female surgeons: a population based matched cohort study. BMJ. 2017;359:j4366.

14. Unwin E, Woolf K, Wadlow C, et al. Sex differences in medico-legal action against doctors: a systematic review and meta-analysis. BMC Med. 2015;13:172.

15. Ashton-James CE, Tybur JM, Grießer V, Costa D. Stereotypes about surgeon warmth and competence: the role of surgeon gender. PLoS One. 2019;14(2):e0211890.

16. Kim EE, Klein AL, Lartigue JW, et al. Diversity in neurosurgery. World Neurosurg. 2021;145:197-204. 
17. Prideaux D, Roberts C, Eva K, et al. Assessment for selection for the health care professions and specialty training: consensus statement and recommendations from the Ottawa 2010 Conference. Med Teach. 2011;33(3):215-223.

18. England P, Levine A, Mishel E. Progress toward gender equality in the United States has slowed or stalled. Proc Natl Acad Sci U S A. 2020;117(13):6990-6997.

19. Crebbin W, Campbell G, Hillis DA, Watters DA. Prevalence of bullying, discrimination and sexual harassment in surgery in Australasia. ANZ J Surg. 2015;85(12):905-909.

20. Stephens EH, Heisler CA, Temkin SM, Miller P. The current status of women in surgery: how to affect the future. JAMA Surg. 2020;155(9):876-885.

\section{Disclosures}

The authors report no conflict of interest.

\section{Correspondence}

Katharine J. Drummond: kate.drummond@mh.org.au.

\section{INCLUDE WHEN CITING}

DOI: 10.3171/2020.12.FOCUS20949. 